\title{
EFEITOS DO ISOLAMENTO SOCIAL (COVID-19) SOBRE A MOBILIDADE DE NONAGENÁRIOS E CENTENÁRIOS: ESTUDO AMPAL
}

Josemara de Paula Rocha; Pontifícia Universidade Católica do Rio Grande do Sul (PUCRS); josemara.rocha@hotmail.com

Marlon Cássio Pereira Grigol; PUCRS; marlonfisio@gmail.com

Álvaro Luiz Fortes; PUCRS; alvarolforte@gmail.com

Ana Paula Tiecker; PUCRS; anapaulatiecker@hotmail.com

Renata Breda Martins; PUCRS; nutri.renatamartins@gmail.com

Viviane Maura Rubert; PUCRS; vivirubert@hotmail.com

Ângelo José Gonçalves Bós; PUCRS; angelo.bos@pucrs.br

- Projeto de extensão Atenção Multiprofissional ao Longevo (AMPAL) da PUCRS, Porto Alegre, Brasil - Escola de Medicina da PUCRS, Porto Alegre, Brasil

\section{RESUM0}

Introdução: A diminuição da mobilidade pode estar relacionada ao risco de quedas e ao isolamento social da COVID-19 principalmente em nonagenários e centenários. Objetivo: Investigar se o isolamento social da COVID19 alterou a mobilidade e força de membros inferiores em nonagenários e centenários. Métodos: Estudo longitudinal e observacional envolvendo nonagenários e centenários participantes do projeto Atenção Multiprofissional ao Longevo (AMPAL), avaliados quanto a mobilidade (facilidade de levantar-se de uma cadeira com e sem as mãos) e força de membros inferiores (teste de levantar e sentar -TLS). O teste foi considerado satisfatório se 5 repetições foram realizadas em 15 segundos. Foram calculadas e comparadas médias e frequências. Resultados: Participaram 31 nonagenários e centenários (74\% mulheres, 93 33,4 anos) que realizaram as avaliações em uma das entrevistas de 2016 a 2018 e entre abril e agosto de 2020 . A mobilidade piorou em $7 \%$ dos participantes para levantar-se da cadeira com as mãos e nenhuma para realizar o movimento sem o auxílio das mãos. No TLS, 21\% $(n=6)$ tiveram desempenho satisfatório antes da pandemia, e durante o isolamento, 22\% $(\mathrm{n}=5)$. Conclusão: A maioria apresentou desempenho insatisfatório na mobilidade e no TLS tanto antes quanto durante o período pandêmico. O que indica que os longevos mantêm o risco aumentado para quedas, fraqueza de membros inferiores, diminuição da mobilidade e que podem estar em processo de decréscimo funcional. No entanto, o período de quarentena imposto (5 meses até o momento) ainda é curto para observar seus efeitos sobre o desempenho.

Palavras-chave: Idoso de 80 Anos ou mais; Saúde Pública; Atividades Cotidianas; COVID-19; Pandemias.

Agradecimentos: O presente trabalho foi realizado com apoio da Coordenação de Aperfeiçoamento de Pessoal Nivel Superior - Brasil (CAPES) - Código de Financiamento 001. 